\title{
When News Goes Online. A Cross-Media Analysis of Editorial Logics and Consumers' Feedbacks in the Printed, Online and Facebook Versions of the Italian Newspaper la Repubblica
}

\begin{abstract}
As a consequence of the advent and diffusion of new media, one of the most accredited hypotheses in the realm of mediatization theory has been that the essential prerequisites of mediatization would have slowly started to disappear. On the contrary, we hypothesize that the unprecedented knowledge about users' preferences given to media companies would be reflected in the logics of news production, which would shift from being guided by internal logics and standards of newsworthiness to be driven by an audience-oriented commercial logic. Therefore, we expect storytelling techniques to prevail in online news production, with soft news becoming progressively prevalent moving from traditional to new media. We address our hypothesis performing a cross-media analysis of the Italian newspaper la Repubblica, investigating both the different editorial logics underlying the selection and framing of contents as well as the relationship between the general news frame and the level of readers' engagement. In our findings, soft news prevails regardless of the platform, also following a positive trend as we move towards Facebook. Moreover, soft news seems to be able to foster a higher level of users' engagement as expressed in terms of likes and shares, while hard news prevails in commenting activities.
\end{abstract}

Keywords: mediatization, hybridization, Facebook, media logics, news consumption

\section{Introduction}

Since the early 1990s, the growing interest in mediatization theory as a new research field of political communication has contributed to shift the attention from the analysis of media contents and their influence on the audience, to the study of media platforms and their institutional and technological essence. Given the multifaceted nature of mediatization as a crossfield phenomenon which "simultaneously facilitates centrifugal, centripetal, homogenizing and differentiating processes" (Hepp, Hjarvard, \& Lundby, 2010, p. 226), the concept has been used by scholars both to refer to those changes affecting media and their modes of communication as well as to interpret the wide range of transformations resulting from the growing media influence on other cultural and societal spheres.

With regard to the different emphasis accorded either to media as institutions in their own right or to the role they play as societal agents of cultural production, in mediatization theo$r y$ we might identify two main approaches (Couldry \& Hepp, 2013): the institutionalist (see Altheide \& Snow, 1979 among others) and the social-constructivist (see Krotz, 2009; Hepp, 2012 among others).

* University of Milan, Italy, f.arcostanzo@gmail.com.

** University of Milan, Italy, alice.pulvirenti01@libero.it. 
From an institutionalist perspective mediatization refers to "the forms, practices and experiences associated with the dominant media and institutions of the broadcast era, and particularly television" (Hoskins, 2009, p. 148). Within the institutionalist tradition, media should thus be considered as an independent institution with its own set of rules and practices, whose growing influence on different fields of society determines an adaptation of external social actors and institutions to media logic, intended as the process through which media present and transmit information (Altheide \& Snow, 1979; 1988; 1991). The concept of mediatization as coined by institutionalists is particularly useful for analyzing the transformation of many disparate social and cultural processes into forms or formats suitable for media representation. Nevertheless, the linearity of the process described has been widely questioned during the last years, becoming the subject of different criticisms that could be brought back to four main reasons. First of all, the monolithic definition proposed seems not to be working for capturing the multi-polar nature of society (Bourdieu, 1993). Secondly, the institutionalist conceptualization of mediatization appears to be limited in time, applicable only since the moment in which media have become independent institutions (since 1980s according to Hjarvard, 2008). Thirdly, the institutionalist approach lacks in considering how the rise of a new digital network space of communication has contributed to the redistribution of assets and to the relative distribution of rules and resources characterizing the logics of traditional media (Jensen, 2013). Finally, the reference to a single media logic as if operating in one direction and at the same speed seems to be reductive, as underlined even more by the growth of the Internet (Couldry, 2008).

Furthermore, social-constructivists refuse to acknowledge media as a single institution, attributing to them a symbolic power through which they would not only influence what social actors and audiences do, but first and foremost their ability to describe social life (Block, 2013). Mediatization is here conceived as a "process of communicative construction of socio-cultural realities enacted by different and various media" (Couldry \& Hepp, 2013, p. 196). Although conceptualizing mediatization as a process resulting from different intervening and intertwined factors the social-constructivist approach has the merit to grasp the multi-polar character of contemporary society, such a definition seems to be too blurring if one wants to capture macro-level dynamics (Hjarvard 2008).

In recent years, several scholars (Altheide, 2013; Hjarvard, 2008; Jensen, 2013) have shed light on the necessity to operate a brainstorming on the concept of mediatization in order to find a common thread between the linearity of the institutionalist approach and the too much blurring conceptualization given by social-constructivists (Couldry \& Hepp, 2013).

\section{Commercial logics, new media and hybridization: towards a "third way" in mediatization studies?}

With the rise of web 2.0 and the increasing globalization of media systems since the late 1990 s, scholars have started to call for a new conceptualization of mediatization which takes into account both the structuring role of the media as institutions of cultural production as well as the reflexivity of media logics reproduced in - and reshaped through - social interactions (Altheide, 2013; Hjarvard, 2008; Jensen, 2013). This conception of media can be particularly powerful to investigate how the increasing hybridization in the production of newspaper contents, from a traditionally printed form to their by now normalized spread out in the world of social media, is eventually affecting the process of selection and framing of political news. 
With regards to the advent and diffusion of new media, since the beginning of 2000s one of the most discussed hypotheses was that the essential prerequisites of mediatization would have slowly started to disappear, with new media exerting a sort of dis-mediatizing effect (Schulz, 2004). This hypothesis is widely discussed by Schulz (2004), who in his article Reconstructing mediatization as an analytical concept, identifies three possible future scenarios: an optimistic, a sceptical and a moderate one. According to the optimistic answer, new media increasingly de-massify and individualize communication (Castells, 2004), thus contributing to enhance users self-selection and self-determination, in contrast to the standardization of information carried out by television. From a mediatization perspective, the increasing de-standardization and selectivity produced by the internet in the long-run would bring to a loss of dependency on media gate-keeping power, with no more mediation and adaptation to the media logic by social actors. On the other hand, according to the sceptical answer the rise of new media simply determines new modes of mediatization. Filtering effects would thus remain, making a full autonomy impossible for users, while new forms of standardization would be reproduced through the creation of new languages. Finally, the moderate answer imagines a future scenario characterized by a convergence between old and new media. Moreover according to this view the demand for entertainment and infotainment (the so-called soft news) is expected to expand much more than the demand for hard news, thus reproducing in the consumption of online news the same standardization and mediation effects characterizing old media.

The moderate answer proposed by Schulz (2004, p. 12) has the merit to outline a conception of new media as "nothing but hybrid versions, or reconfigurations, of the conventional media" On the other hand, if the moderate scenario might be still appropriate to describe the present situation in most of Western countries, we expect that the strategic evaluation of media affordances characterizing on-line platforms such as Facebook would affect editorial logics in a way that channels them towards the production of ever more popular or audience-oriented contents. The standardization and mediation effects characterizing the old media would thus not only be reproduced, but also amplified while moving from traditional to new media.

The review of the concept of media logic operated by Landerer (2013) might be useful to clarify our hypothesis. According to, in fact, media companies are mainly driven not by one, but by two competing logics: an audience-oriented commercial logic and a normatively oriented public logic. In the normative logic (see Bourdieu, 1999), social or public responsibility "takes place over market considerations: what is important is not how much a media company sells, but what it produces, and what it should contribute to a democratic society's public debate" (Landerer, 2013, p. 245). In the commercial logic (Hamilton, 2004; McManus, 1994), "media actors are mainly market-driven and economic considerations are the dominant principles that guide news selection, organization, and production" (Landerer, 2013, p. 243). According to Landerer (2013), the normative aspects of news production sometimes, though not always, clash with the efficiency considerations summarized under commercial logic (p. 245):

Owing to economic constraints, it is likely that commercial logic is stronger in privately organized than in public news companies, which have more scope to implement the normative standards developed under the concept of public logic. But in a globalized world - whereby globalization refers to economic integration and technological progress - profit-oriented media companies act as large transnational firms that compete with public news organizations for airtime [...]. In this process, commercial and public logics enter into 
direct competition with each other, not only among different companies, but also within one company's limited temporal and financial resources.

Online publishing gives news media unprecedented knowledge about users' preferences and, as a consequence, unprecedented opportunities to instantly 'feed' the audience what they apparently want rather than guessing or knowing what they liked last month (Strömbäck \& Karlsson, 2011, p. 648). Thus, while only a minority of users may be actively attempting to influence and participate in news production processes, all users of online news media may be indirectly involved through their choice of online news stories (Landerer, 2013, p. 648). In this regard, our hypothesis is that the increased influence of users' preferences may shift the logic of news production from being driven by internal logics and standards of news-worthiness, to be driven more by an audience-oriented commercial logic. As a consequence, we expect storytelling techniques such as "simplification, polarization, intensification, personalization, visualization, stereotyping, and particular ways of framing the news" (Strömbäck \& Esser, 2009, p. 213) to become prevailing in online news production, with soft news becoming progressively more prevalent moving from traditional to new media. Finally, we expect that the changes in editorial logics would be reflected in the way in which users engage with contents, provide feedbacks or reproduce typical media frames and logics in comments.

\section{Research questions and hypotheses}

If considered in light of the increasing hybridization of news contents, this renewed theoretical perspective opens up a space for two main RQs:

RQ1: Does the switching of contents from offline to online/social media platforms determine a popularization of media logic(s)?

RQ2: Do the specific affordances characterizing an online platform affect the way users engage with contents?

According to the theoretical framework outlined in the introduction of this article, the hypotheses driving our research are the following:

HI1: As regards logics of news production, we expect to find a higher percentage of soft news: (1) moving from the offline to the online version of the newspaper la Repubblica and (2) moving from the online version of the newspaper to its Facebook fan-page.

HI2: As regards logics of news consumption, we expect to find, on average, a higher level of users' engagement associated to soft news.

HI3: On the overall Facebook we also expect a higher spread of soft news with respect to the hard ones, measured through the level of users' engagement.

Furthermore, we are interested in investigating if there is any specific pattern associated to the activities of liking, sharing and commenting. 


\section{Methodology}

\subsection{Data collection}

In order to address our research questions and test our hypotheses, we randomly chose a one-week period of analysis ${ }^{i}$ during which:

1. We have collected all the daily printed copies of the newspaper la Repubblica ${ }^{\mathrm{ii}}$, the $2^{\text {nd }}$ most widespread newspaperii in Italy and the $1^{\text {st }}$ one in the ranking of newspaper websites ${ }^{\text {iv }}$;

2. We have archived all the homepages of the online version of la Repubblica ${ }^{v}$ through The Way Back Machine ${ }^{v i}$;

3. We have collected all posts published on la Repubblica Facebook fanpage as well as their relative engagement metrics through Netvizz, a data collection and extraction application that allows researchers to export data in standard file formats from different sections of the Facebook social networking service (Rieder, 2013).

\subsubsection{Offline and online newspaper}

In order to investigate which logics and standards of newsworthiness drive the selection of contents from a top-down perspective, we decided to take into consideration only articles appearing in the offline front pages, thus excluding any other news inside the journal. Our intention was to try to apply the same criteria even to the online version of the journal, since our main goal was properly that of a cross-media comparison, but, unfortunately, we could not find in the literature any satisfying reference to a correct definition of what can be considered as the equivalent of an offline front page in the online version of a newspaper. In order to overcome this problem, we thus decided to classify every day the same number of articles we found on the printed version, simply starting from the top of the page.

\subsubsection{Repubblica's Facebook fan-page}

Through the Netvizz application (Rieder, 2013) we have downloaded a dataset containing all the information and engagement metrics for each post published in the selected days on la Repubblica Facebook fan-page. In particular, for each post we have been able to retrieve: 1) the publishing date; 2) the URL of the article published in the post; 3) the number of likes, shares, comments and level of engagement gathered by each post. Although only the metrics indicated at points 1) 2) and 3) have been taken into account for the purposes of this article, it is important to know that Netvizz allows us to obtain as well information about 4) the type of post (video, link, picture) and 5) the text of the post message ${ }^{\text {vii }}$.

\subsection{Method}

In order to be able to grasp both top-down news production logics as well as bottom-up patterns of news consumption, we decided to analyze our collected data combining a qualitative approach focused on news frames with a more quantitative use of numerical indicators such as engagement metrics and their components (likes, shares, comments). More specifically, we firstly performed a qualitative content analysis of all news articles present in our dataset in order to investigate how do editorial logics may or may not change across the different media platforms on which la Repubblica is edited. 
In the second part of our study we have therefore crossed the results coming from our content analysis with Facebook engagement metrics, an operation that allows us to see more in depth which kind of news frame, whether hard or soft, do stimulate higher (or more active) levels of users' reactions. To complete the analysis, we also experimentally used additional engagement metrics retrieved through the Like Scraper (see below) in order to compare news consumption on la Repubblica fan-page with their subsequent spread across the overall Facebook.

\subsubsection{Qualitative content analysis of hard versus soft news frames}

The underlying idea in our research design is to understand whether an increasing hybridization of the information environment could give boost to a likewise increasing mediatization in news production and consumption. In this regard we decided to look at the concept of hard vs. soft news as a proxy of mediatization, thus classifying our sample of 628 articles (see table 1.1) as hard, medium or soft news ${ }^{\text {viii }}$. Our content analysis of news frames has then been performed adopting a qualitative approach through which we induced our classification of contents relying on the operationalization of hard vs. soft news given by Reinemann, Stenier, Scherr and Legnante (2012). In their review of the concept, the authors propose a multi-dimensional operationalization that takes into account the topic, content, focus and style of news:

The more news item is politically relevant, the more it reports in a thematic way, focuses on the societal consequences of events, is impersonal and unemotional in its style, the more it can be regarded as hard news. The more a news items is not politically relevant, the more it reports in an episodic way, focuses on individual consequences of events, is personal and emotional in style, the more it can be regarded as soft news (Reinemann et al. 2012, p. 14).

As far as the topic dimension is concerned, a crucial role has been given by Reinemann and colleagues to the political relevance of news, operationalized as the reference to societal actors, decision-making authorities, policy plan and actors'concerns.

Even though we agree with Reinemann and colleagues in considering the political relevance of an article as particularly crucial for its classification as hard vs. soft, we found that his operationalization was somehow too strict for the purposes of our research. In particular, we realized that focusing mainly on the feature of political relevance would have led us to miss some important information concerning news, whose topic is not related to politics such as those treating chronicles or current events. In fact, as resulted by preliminary analysis on a sub-set of articles, following Reinemann and collaborators (2012), all our articles except political ones would have been classified as soft news, i.e. included articles about important current events and reported with a sacerdotal and serious frame. For these reasons we decided to introduce a third category, that of medium news, in order to be able to grasp grey zones and blurring boundaries in our classification of news. Furthermore, as we believed another crucial aspect to be included in our investigation is that related to the popularization of political contents entailed in the concept of mediatization (Mazzoleni \& Sfardini, 2009), we decided to add two more indicators of focus and style, namely: 1) the prevailing reference to ideological positions and actions versus scandals or gossip concerning the actors involved; 2) the serious versus ironic style of reporting adopted by the journalist.

According to Mazzoleni and Sfardini (2009), two of the major outcomes within the process of mediatization of society are indeed the increasing spectacularization and personalization 
of politics, which seem to have led to phenomena such as commodification of politics or lifestyle politics (Bennet \& Entman, 2001). In light of such considerations, our classification of contents basically relies on the three following categories:

Hard news (2): the more a news is politically relevant, framed in a thematic way, focused on the societal consequences of events and on the ideological positions and substantive actions of actors involved, reported in an impersonal, unemotional and serious style, the more it can be regarded as hard news.

Medium news (1): the more a news is connected to chronicles or current events, framed in a thematic way, focused on the societal consequences of events and on the ideological positions and substantive actions of actors involved, reported in an impersonal, unemotional and serious style, the more it can be regarded as medium news. We consider medium news as well those news that are politically relevant, but framed in an episodic way, focused on the individual consequences of events and on gossip and aspects of the private life of actors involved, reported in a more personal, emotional and ironic style.

Soft news (0): the less a news is politically relevant, but framed in an episodic way, focused on the individual consequences of events and on gossip and aspects of the private life of actors involved, reported in a personal, emotional and ironic style, the more it can be regarded as soft news.

\subsubsection{Engagement metrics}

In the second part of our work we aim at investigating the diffusion of news contents on Facebook. More specifically, we are interested in analysing the level of engagement driven respectively by soft and hard news. In Facebook marketing, engagement is a composite measure constituted by the sum of three indicators: 1 ) the number of likes; 2 ) the number of shares; 3) the number of comments.

We are interested in analysing the relationship between hard and soft news and their correspondent ability to drive users' engagement on la Repubblica Facebook fan-page.

Yet, we are interested as well in understanding the further diffusion of contents throughout the overall Facebook, therefore including in this second step all likes, shares and comments gathered by a given news not only on la Repubblica fan-page but also on other Facebook pages (i.e. personal profiles, groups and other fan-pages). To do so, we have used the Like Scraper tool ${ }^{\mathrm{ix}}$, a script which directly queries the Facebook application and retrieves the number of likes, shares and clicks for any given URL, querying all the URLs of the articles published on la Repubblica Facebook fan-page. Even though extremely useful, the only limit of the Like Scraper tool is that it is able to retrieve the number of like, share and comments from any URL except for those of Facebook posts, from which it is still unable to extract the same metrics. Therefore, in order to compare the level of engagement gathered by news shared on la Repubblica fan-page with that obtained on the overall Facebook, we have excluded from our dataset all posts without any external link, while performing content analysis of all ${ }^{\mathrm{x}}$ the other articles.

In Table1.1 and Table1.2, we present, respectively, the number of articles on which content analysis has been performed, by type of support (Table 1.1.) as well as their different engagement metrics per day, both on la Repubblica fan-page and throughout the overall Facebook (Table 1.2.). At a first glance, we can also see that the diffusion of news on Facebook goes way beyond the pure consumption of news on la Repubblica fan-page. 
Table 1.1. Summary of analysed data, by type of support.

\begin{tabular}{|c|c|c|c|c|c|c|c|c|}
\hline & $11 / 05 / 2015$ & $12 / 05 / 2015$ & $13 / 05 / 2015$ & $14 / 05 / 2015$ & $15 / 05 / 2015$ & $16 / 05 / 2015$ & $17 / 05 / 2015$ & Total \\
\hline Offline & 11 & 12 & 11 & 13 & 10 & 13 & 12 & 82 \\
\hline Online & 11 & 12 & 11 & 13 & 10 & 13 & 12 & 82 \\
\hline Facebook & 51 & 59 & 63 & 54 & 63 & 46 & 50 & 386 \\
\hline Total & 73 & 83 & $8_{5}$ & 80 & 83 & 72 & 74 & 550 \\
\hline
\end{tabular}

Table 1.2. Comparison between the daily total number of likes, shares, comments and level of engagement gathered by articles on la Repubblica fan-page and throughout the overall Facebook.

\begin{tabular}{|c|c|c|c|c|c|c|c|c|}
\hline & \multicolumn{3}{c}{ Like } & \multicolumn{2}{c}{ Share } & \multicolumn{2}{c}{ Comments } \\
\hline & Repubblica & All & Repubblica & $A l l$ & Repubblica & $A l l$ & Repubblica & $A l$ \\
\hline $11 / 05 / 2015$ & 64591 & 194467 & 22793 & 48577 & 12297 & 54876 & 99681 & 297920 \\
\hline $12 / 05 / 2015$ & 72798 & 202526 & 45148 & 66376 & 11070 & 80395 & 129016 & 349297 \\
\hline $13 / 05 / 2015$ & 54162 & 106555 & 24526 & 39066 & 8250 & 29286 & 86938 & 174907 \\
\hline $14 / 05 / 2015$ & 77416 & 195569 & 37011 & 59648 & 13026 & 55093 & 127453 & 310310 \\
\hline $15 / 05 / 2015$ & 81635 & 171482 & 26480 & 50370 & 15363 & 45477 & 123478 & 267329 \\
\hline $16 / 05 / 2015$ & 81550 & 133237 & 23485 & 36876 & 14113 & 28908 & 119148 & 199021 \\
\hline $17 / 05 / 2015$ & 87709 & 183838 & 23335 & 46355 & 9005 & 31807 & 120049 & 262000 \\
\hline Total & 519861 & 1187674 & 202778 & 347268 & 83124 & 325842 & 805763 & 1860784 \\
\hline
\end{tabular}

\subsection{Results}

In the following paragraphs our findings are presented. First of all, logics of news production are investigated, through a comparison between the offline and online front page of the newspaper la Repubblica. Secondly, we analyse users' activities (liking, sharing, commenting) on la Repubblica Facebook fan-page in relation to the different types of news (hard, medium, soft) present there, in order to identify the different patterns of news' consumption. Finally, we suggest a comparison between the consumption of news on la Repubblica Facebook fan-page and their diffusion across the overall Facebook, in order to test whether our initial assumptions are confirmed even when moving from the news source to the overall network.

\subsubsection{News distribution: offline, online and Facebook}

Figure 1.1. displays a comparison between the percentage of hard, medium and soft news published on the offline and online version of the newspaper la Repubblica. As we can see from the graph, in the offline version of the newspaper the more represented category in our weekly sample is the one of soft news $(40.22 \%)$, followed by hard $(37.80 \%)$ and medium news $(21.95 \%)$. Moving to the online version of the newspaper an even wider space is given to the category soft news, which with a percentage of $51.22 \%$ includes the majority of published articles. Even in this case, soft news is followed respectively by the categories of hard (26.83\%) and medium (21.95\%) news. 
Figure 1.1. News production by type of content on the online and offline versions of the newspaper la Repubblica, \% of the weekly news.

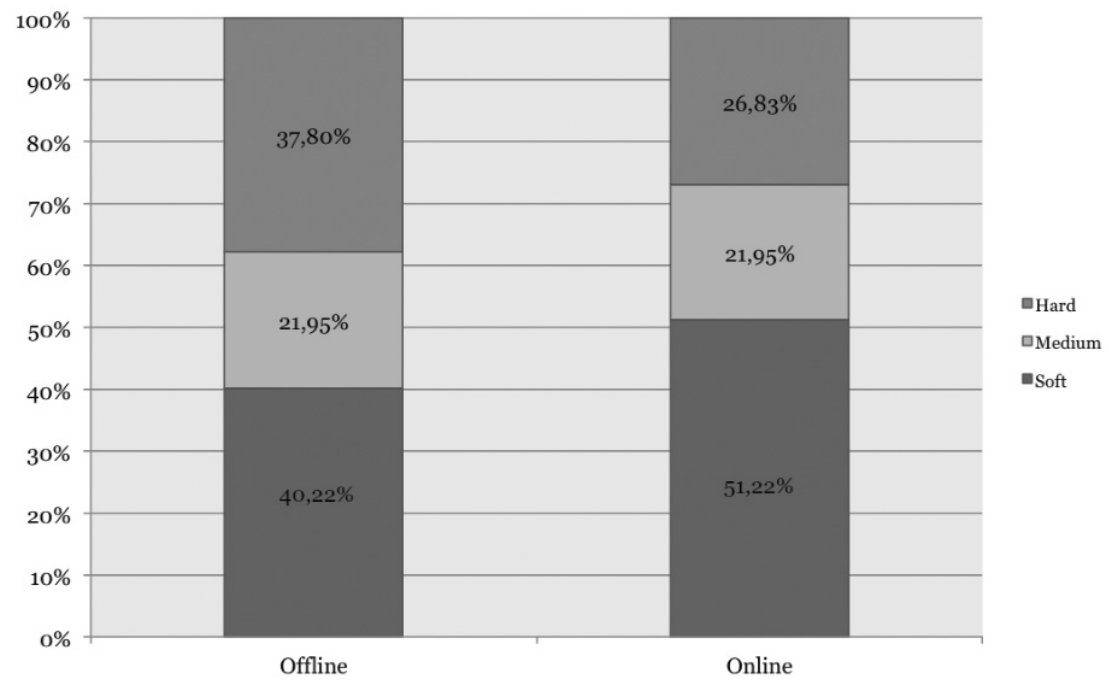

In Figure 1.2., the same analysis is reproduced with regards to the articles shared by $l a$ Repubblica's newsroom on the newspapers Facebook fan-page. As we can see from the graph, also in this case a wider space is given by far too soft news (63.73\% out of the weekly total). Differently from the offline and online versions of the newspaper, in the analysed week, medium news occupy a wider space on the Facebook fan page (19.95\%) if compared to hard news $(16.32 \%)$. Yet, while the prominence of soft news is undeniable, the difference between medium and hard news should be taken with care and further investigated in future research.

Figure 1.2. News distribution by type of news on the Facebook fan-page of the newspaper la Repubblica, \% of the weekly news.

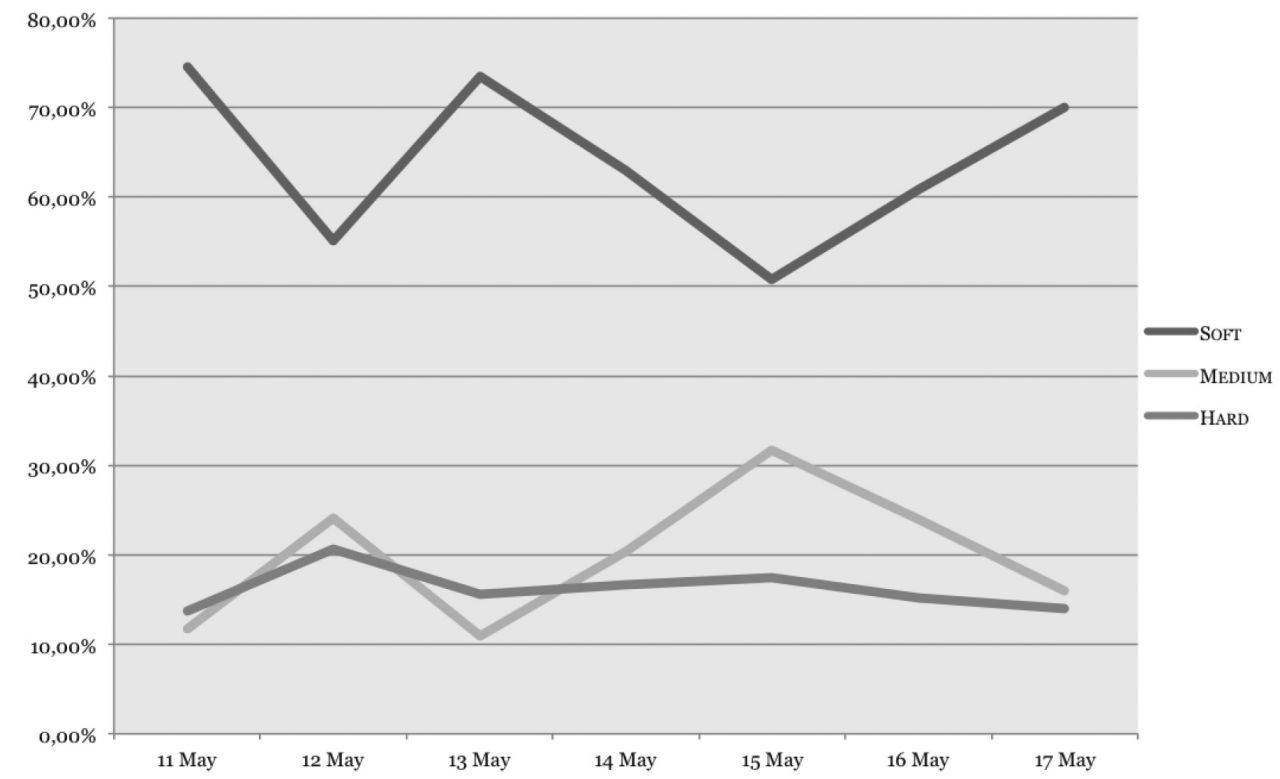




\subsubsection{News consumption: liking, sharing and commenting on}

\section{la Repubblica Facebook fan-page}

In the analysis of news consumption, our main hypothesis is that production logics would be reflected in users' preferences, expressed through the activities of liking, commenting and sharing. Moreover, we are interested in identifying eventual specific patterns characterizing the three activities. In order to weight our results, instead of the total count of likes, shares and comments, we have used for each metric the weighted average per day (e.g. total number of likes per soft news / total number of soft news published per day).

Figure 1.3. displays our results for what concerns users' liking behaviour. As we can see from the graph the general expected trend is confirmed, with soft news gathering the higher number of likes (1563 likes, average per day), followed by medium news (1207) and hard news (671), with 1347 being the average number of likes per day (calculated on the total of news published, regardless of the type of news). The same trend is confirmed with regards to users' sharing behaviour, with soft news driving the higher number of shares (655 shares, average per day), followed by medium news (347) and hard news (235), with 525 being the average number of shares per day (see Figure 1.4.).

Figure 1.3. Number of likes by type of news on la Repubblica Facebook fan-page, weighted average per day (counts).

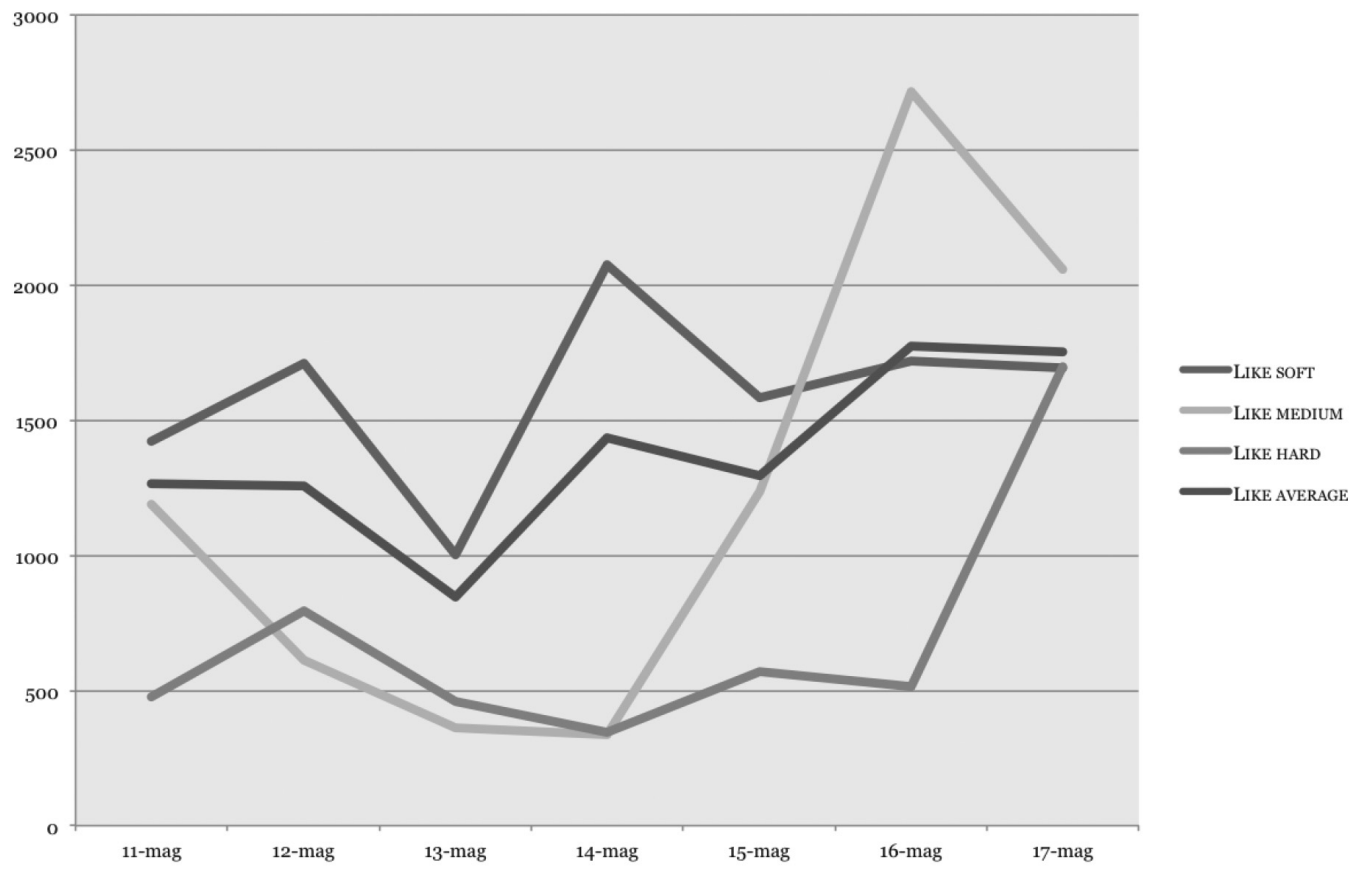


Figure 1.4. Number of shares by type of news on la Repubblica Facebook fan-page, weighted average per day (counts).

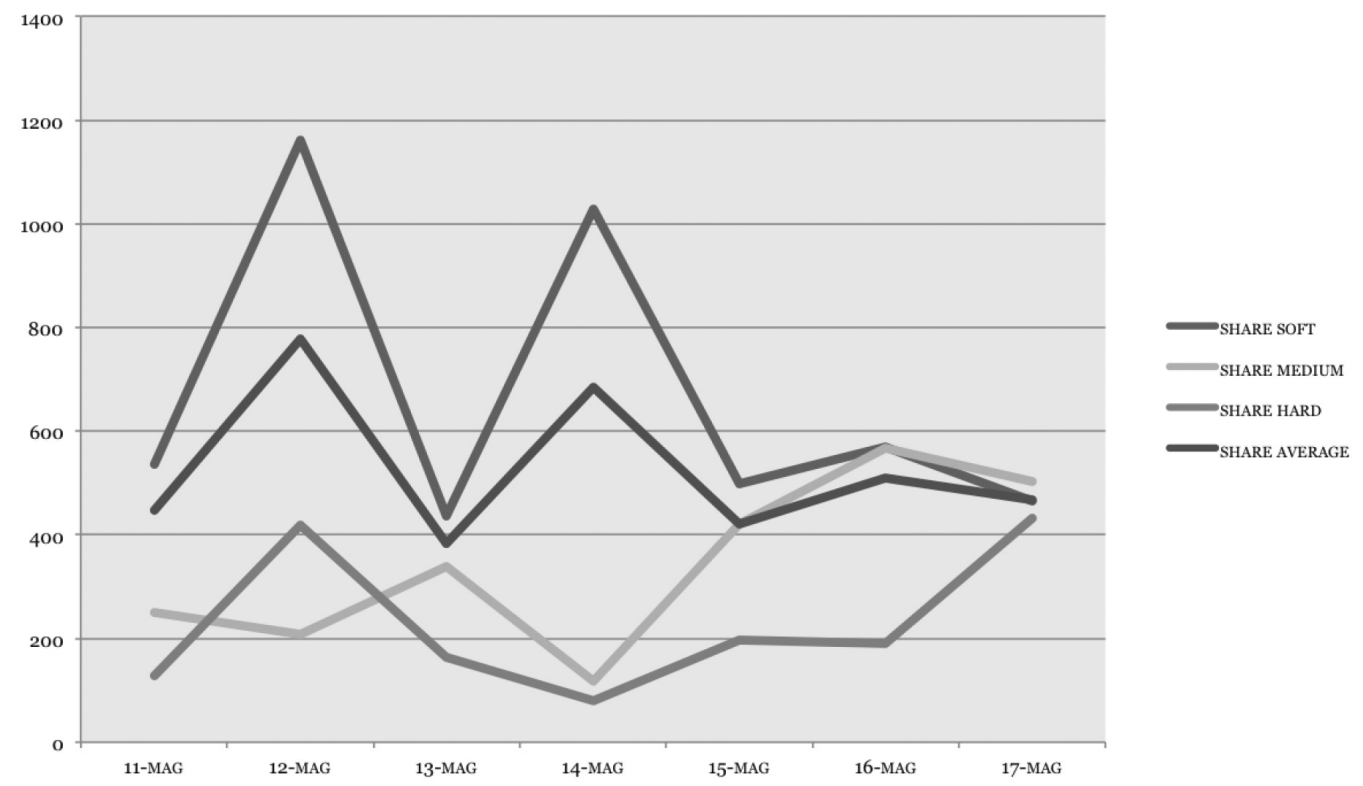

The analysis of users' commenting behaviours presents different results, which deserve a special consideration (see Figure 1.5.). In fact, while our hypothesis about users' preference for soft news is confirmed by their liking and sharing activities, in their commenting activities readers seem to adopt a different logic. As suggested by the graph, while analysing commenting activities users' preference seems to go to medium (308 comments, average per day) and hard (275 comments, average per day) news, while soft news gather "only" an average of 171 comments per day, with 215 being the average number of comments per day ${ }^{x i}$. Although further research are needed to confirm the existence of a specific pattern characterizing users' commenting activity, our results suggest that it relies on the activation of a different logic which gives preference to hard and medium news instead of to soft news. 
Figure 1.5. Number of comments by type of news on la Repubblica Facebook fan page, weighted average per day (counts).

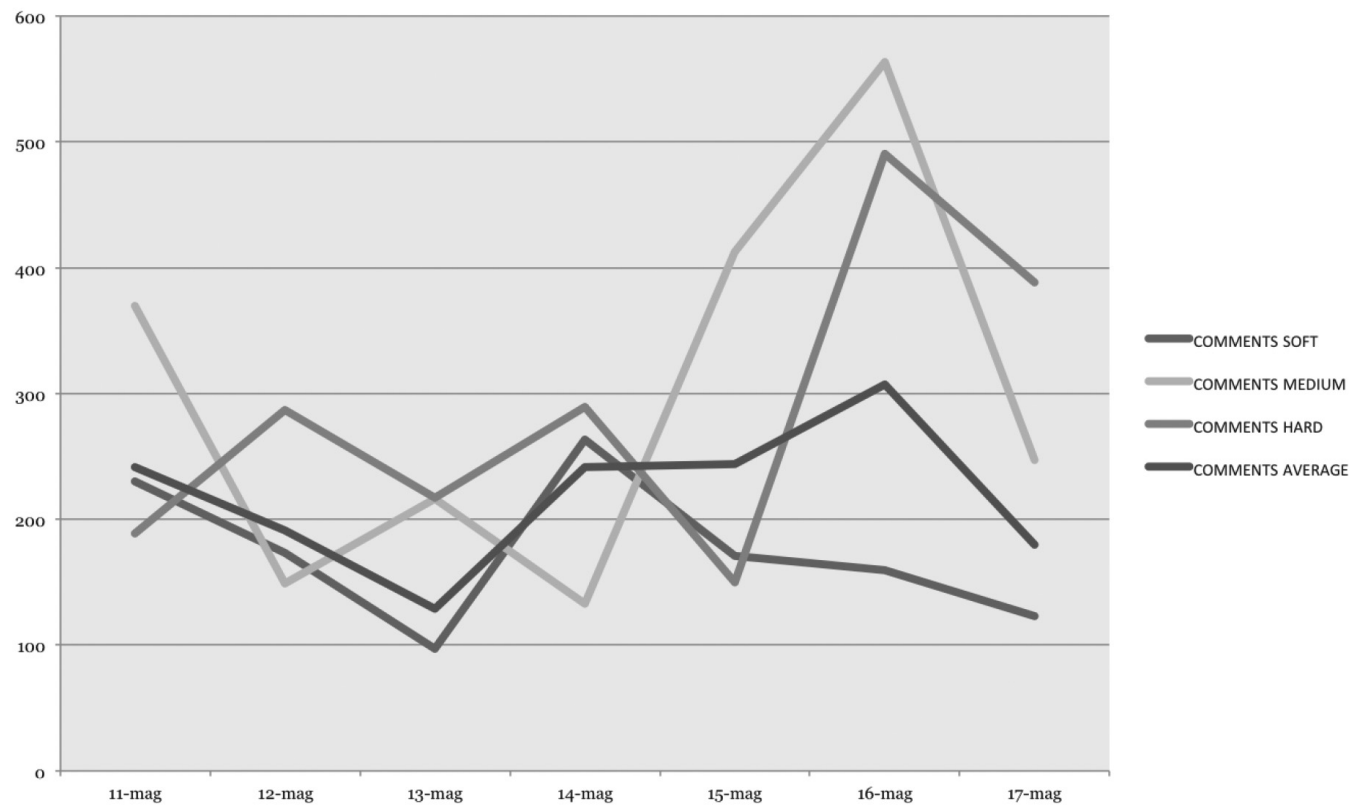

\subsubsection{News consumption: engagement trends in the overall Facebook}

Figure 1.6. displays the results of our comparison between the level of total engagement (sum of likes, shares and comments) gathered by each type of news on la Repubblica Facebook fan-page and in their spread on the overall Facebook. As suggested by the picture, even moving from la Repubblica Facebook fan-page to the overall social network, soft news remain the type of news which stimulates an higher level of users' engagement (2390 engagement actions, average per day), followed by medium (1863) and hard (1181) news, with 2087 being the average number of engagement actions per day. 
Figure 1.6. Engagement actions by type of news: a comparison between la Repubblica fanpage and on the overall Facebook, weighted average per day (counts).

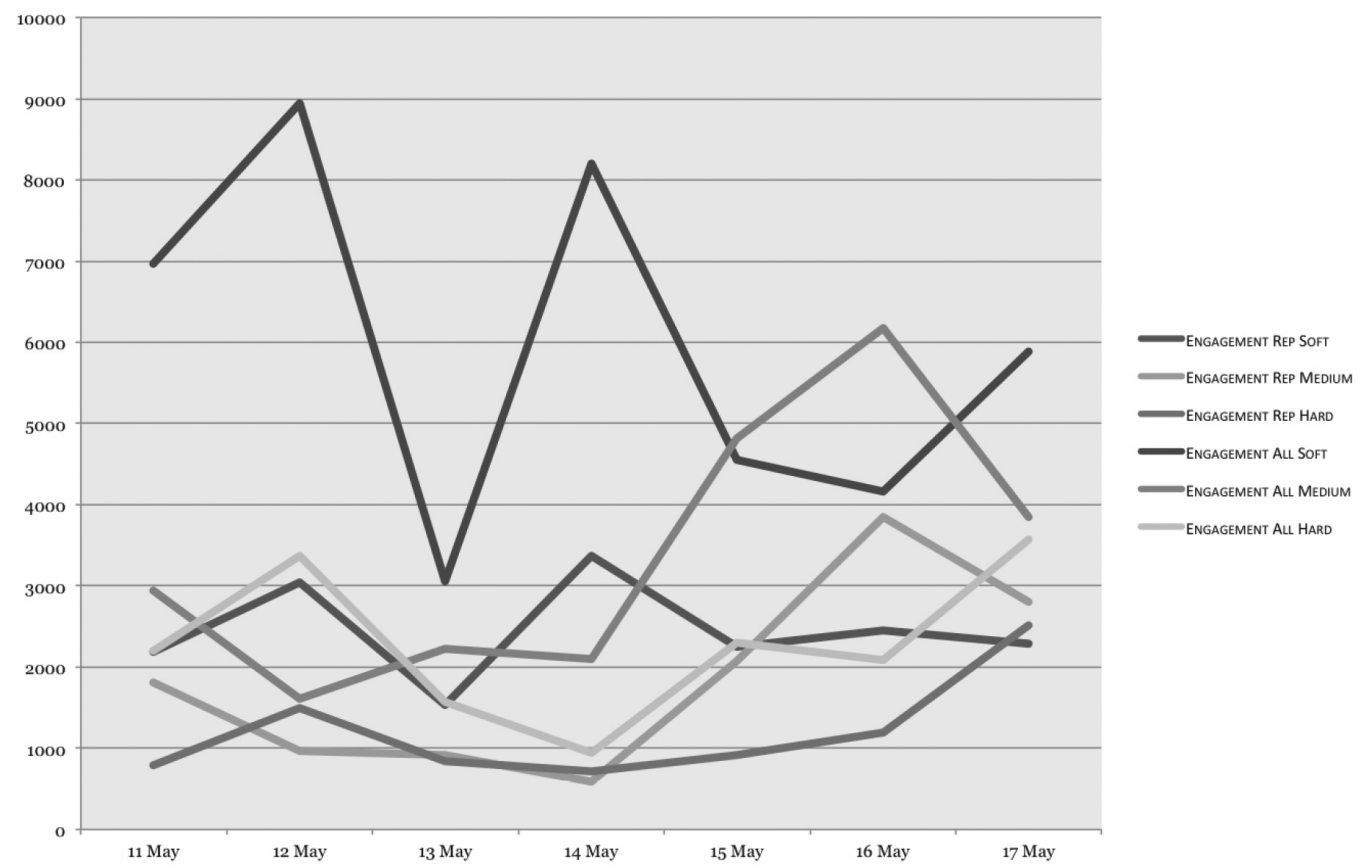

Although the relationship between the publication of news on la Repubblica Facebook fanpage and their diffusion on the overall Facebook is only sketched in this article, it is interesting to see how the level of engagement gathered by news on the overall Facebook is more than the double of the one they are able to stimulate in the platform on which they are originally published, la Repubblica Facebook fan-page (Table 1.3.).

Table 1.3. Engagement actions by type of news: a comparison between la Repubblica fanpage and the overall Facebook, weighted average per day (counts).

\begin{tabular}{|l|c|c|c|c|}
\multicolumn{2}{|c}{ soft news } & medium news & hard news & average \\
\hline La Repubblica fanpage & 2390 & 1863 & 1181 & 2087 \\
\hline Overall Facebook & 5961 & 3559 & 2302 & 4821 \\
\hline
\end{tabular}

As a consequence, even from this first analysis we can see how, in the changed logics of news diffusion and consumption which characterize the era of social media, readers tend to read and get engaged with news not only through the news platforms, but even more through news' appearances on their Facebook timeline, e.g. because shared by users' Facebook friends. What instead doesn't change, even when moving to the overall Facebook, is users' preference for soft news, confirmed by the higher level of engagement associated with this type of content. 


\section{Conclusion}

In contrast to the standardization of information carried out by traditional mass media, the most accredited assumption with regard to the advent and diffusion of new media attributes to them a dis-mediatizing effect, which would lead to an increasing de-massification and individualization of communication thus resulting in a progressive wearing away of the essential prerequisites of mediatization. In light of this hypothesis, the unprecedented power of self-selection and self-determination attributed to users by social media platforms' affordances would result in the over-coming of media dependency, with social actors no more adapting to overwhelming media logic.

We hypothesized that the unprecedented knowledge about users' preferences given to media companies by social media affordances would have been reflected in a shift of the logics of news production, which from being guided by internal logics and standards of newsworthiness would now increasingly, be driven by an audience-oriented commercial logic.

Three research hypotheses have therefore been formulated in order to empirically investigate this general assumption. With regard to the logics of news production, findings seem to confirm the existence of a progressive popularization of contents when moving from the offline to the Facebook version of a newspaper (Figure. 1.1. and Figure 1.2.). Our analysis of the Facebook fan-page suggest that the same effect would affect as well the logics of news consumption, with soft news being the more liked and shared by readers (Figure 1.3. and Figure 1.4.). Albeit further researches are needed in order to generalize our results, in this study we have therefore been able to provide empirical evidence for the existence of an audienceoriented commercial logic driving online news production, as theorized by Landerer (2013). Nevertheless, although trends in the overall level of engagement display a clear preference manifested by readers towards soft contents, our results suggest that a different logic might stand behind commenting activities (Figure 1.5.).

Even though our research hypotheses have been confirmed by the empirical analysis of our collected data, it is worthy to underline the presence of some methodological limits. First of all, although we are aware of the importance of inter-coder reliability in order to assure the validity of qualitative content analysis, we did not have the possibility to train a group of coders working on our analyses. In order to try to overcome this limit, we performed together the content analysis to reach the highest level of consensus at least among us. The second methodological limit concerns the introduction of the category of medium news. As specified in our methodological section, this category has been used to include both news that are not politically relevant but framed in a way that is typical of hard news, as well as news that are politically relevant but framed in a way that is typical of soft ones. Although useful for our purpose, the introduction of this category as well as its composition should probably be subject of a more precise analytical reflection. Finally, in the content analysis of the articles published on la Repubblica Facebook fan page we did not take into account the post messages accompanying the news, which might be useful to better understand editorial logics of news framing on Facebook.

Together with the overcoming of the methodological limits outlined so far, the results presented in this article suggest at least two possible directions for future researches in the field. First of all, the different mechanism which seems to characterize users' commenting behaviour should definitely be further explored, both empirically and theoretically. In this regard, future researches should combine engagement metrics with a deeper analysis of readers' com- 
ments and their interactional dynamics, in order to grasp how media logic(s) are reflected in users' online behaviour. Finally, the last section of this article has outlined how more and more people are consuming and getting engaged with online contents not only through newspapers official fan-pages, but first and foremost grasping news from the flow of 'suggested posts' in their Facebook timelines. Although methodologically challenging, further researches should definitely take it into account in order to truly understand how the advent of social media has revolutionized - and is still revolutionizing - the way in which people get informed.

\section{Acknowledgements}

The authors thank Professor Mauro Barisione and Professor Sergio Splendore for their academic support and the anonymous reviewers for their constructive comments.

\section{Notes}

i from $11 / 05 / 2015$ to $17 / 05 / 2015$.

ii La Repubblica is an Italian daily newspaper, founded in 1976 in Rome by Gruppo Editoriale L'Espresso, led by Eugenio Scalfari, Carlo Caracciolo and Arnoldo Mondadori Editore. Despite at its origins it had a radical-socialist orientation, in the following years it has progressively shifted towards a moderate centreleft political stance.

iii Data available at: http://www.adsnotizie.it/_dati_certificati.asp?azione=filtra, accessed on 15/05/2015.

iv Data available at: http://www.similarweb.com/country_category/italy/news_and_media/newspapers accessed on 15/05/2015.

${ }^{v}$ data available at: http://web.archive.org/web/*/repubblica.ithttp://web.archive.org/web/*/repubblica.it, accessed on 24/05/2015.

${ }^{v i}$ As contents in the homepage are constantly updated throughout the day, before starting our data collection we made a pre-test after which we decided to archive the online homepages at 9:00 a.m. every day, since we verified that this was the moment in which contents online were better comparable with those published on the offline newspaper.

vii For complete information about Netvizz affordances and functioning see Rieder, 2013.

viii For the purpose of this work, we took headlines as unit of analysis.

ix https://wiki.digitalmethods.net/Dmi/ToolLikeScraper accessed on 07/06/2015.

${ }^{x}$ In addition, we have excluded from our content analysis other 7 articles which links were not anymore available at the time of the analysis.

${ }^{x i}$ Although it does not change our overall results, we have noticed an anomaly in liking and commenting users' behavior manifested by a peak of users' engagement with soft news on May 16. We have doublechecked our data in order to assess the cause of the anomaly and individuated that the irregularity is due to the incredible amount of likes and shares gathered by the article "Luxembourg, gay marriage for the Prime Minister: first time in Europe", which according to our coding scheme we believe to have classified correctly as medium news.

\section{References}

1. Altheide, D. L. (2013). Media logic, social control, and fear. Communication Theory, 23(3), 223-238.

2. Altheide, D.L. (1987). Reflections: Ethnographic content analysis. Qualitative sociology, 10(1), 65-77.

3. Altheide, D.L., \& Snow, R.P. (1991). Media worlds in the postjournalism era, New Jersey: Transaction Publishers. 
4. Altheide, D.L., \& Snow, R. P. (1988). Toward a theory of mediation. Communication yearbook, 11, 194-223.

5. Altheide, D.L., \& Snow, R.P. (1979). Media logic. Beverly Hills: Sage Publications.

6. Bennett, W.L., \& Entman, R.M. (2001). Mediated politics: Communication in the future of democracy. Cambridge University Press.

7. Block, E. (2013). A culturalist approach to the concept of the mediatization of politics: The age of "media hegemony". Communication Theory, 23(3), 259-278.

8. Bourdieu, P. (1993). The Field of Cultural Production: Essays on Art and Literature. New York: Columbia University Press.

9 Bourdieu, P. (1999). On television. New York: The New Press.

10. Castells, M. (2007). Communication, power and counter-power in the network society. International journal of communication, 1(1), 29, 238-66.

11. Castells, M. (2004). The network society. A cross-cultural perspective. Massachusetts: Edward Elgar.

12. Couldry, N. (2008). Mediatization or mediation? Alternative understandings of the emergent space of digital storytelling. New Media \& Society, 10(3), 373-391.

13. Couldry, N., \& Hepp, A. (2013). Conceptualizing mediatization: Contexts, traditions, arguments. Communication Theory, 23(3), 191-202.

14. Hamilton, J. (2004). All the news that's fit to sell: How the market transforms information into news. Princeton: Princeton University Press.

15. Hepp, A. (2012). Mediatization and the 'molding force' of the media. Communications, 37(1), 1-28.

16. Hepp, A., Hjarvard, S., \& Lundby, K. (2010). Mediatization-empirical perspectives: An introduction to a special issue. Communications, 35(3), 223-228.

17. Hepp, A., \& Krotz, F. (2008). Media events, globalization and cultural change: An introduction to the special issue. Communications, 33(3), 265-272.

18. Herman, E.S., \& McChesney, R.W. (Eds.) (1997). The global media: The new missionaries of corporate capitalism. London: Cassel.

19. Hjarvard, S. (2008). The mediatization of society: A theory of the media as agents of social and cultural change. Nordicom Review, 29(2), 105-134.

20. Hoskins, A. (2009). Digital network memory. In A. Erll \& A. Rigney (Eds.), Mediation, remediation, and the dynamics of cultural memory, (vol. 10, pp. 91-108). Berlin: de Gruyter.

21. Jensen, K.B. (2013). Definitive and sensitizing conceptualizations of mediatization. Communication Theory, 23(3), 203-222.

22. Knoblauch, H. (2013). Communicative constructivism and mediatization. Communication Theory, 23(3), 297-315.

23. Krotz, F. (2009). Mediatization: A concept with which to grasp media and societal change. In K. Lundby (Ed.), Mediatization: Concept, changes, consequences, (pp. 19-38). New York: Peter Lang.

24. Landerer, N. (2013). Rethinking the logics: A conceptual framework for the mediatization of politics. Communication Theory, 23(3), 239-258.

25. Lengauer, G., Esser, F., \& Berganza, R. (2011). Negativity in political news: A review of concepts, operationalizations and key findings. Journalism, 13(2), 179-202.

26. Mazzoleni, G., \& Schulz, W. (1999). “Mediatization” of politics: A challenge for democracy? Political communication, 16(3), 247-261.

27. Mazzoleni, G., \& Sfardini, A. (2009). Politica pop. Da 'Porta a porta' a 'L'isola dei famosi'. Bologna: Il Mulino.

28. McManus, J. H. (1994). Market-driven journalism: Let the citizen beware? Thousand Oaks: Sage Publications.

29. Reinemann, C., Stanyer, J., Scherr, S., \& Legnante, G. (2011). Hard and soft news: A review of concepts, operationalizations and key findings. Journalism, 6(2), 221-239.

30. Schulz, W. (2004). Reconstructing mediatization as an analytical concept. European journal of communication, 19(1), 87-101. 
31. Rieder, B. (2013, May). Studying Facebook via data extraction: the Netvizz application. In Proceedings of the 5th Annual ACM Web Science Conference (pp. 346-355). ACM.

32. Strömbäck, J., \& Karlsson, M. (2011). Who's got the power? Journalists' perceptions of changing influences over the news. Journalism Practice, 5(6), 643-656.

33. Strömbäck, J. (2008). Four phases of mediatization: An analysis of the mediatization of politics. The International Journal of Press/Politics, 13(3), 228-246.

34. Strömbäck, J., \& Esser, F. (2009). Shaping politics: Mediatization and media environmentalism. In K. Lundby (Ed.), Mediatization: Concept, Changes, Consequences (pp. 205-223). New York: Peter Lang.

35. Turow, J. (2005). Audience construction and culture production: Marketing surveillance in the digital age. The Annals of the American Academy of Political and Social Science, 597(1), 103-121.

36. Ziegele, M., Breiner, T., \& Quiring, O. (2014). What creates interactivity in online news discussions? An exploratory analysis of discussion factors in user comments on news items. Journal of Communication, 64(6), 1111-1138. 